\title{
Total Ozone Columns from the Environmental Trace Gases Monitoring Instrument (EMI) Using the DOAS Method
}

\author{
Yuanyuan Qian ${ }^{1,2,+}$, Yuhan Luo ${ }^{1,+}$, Fuqi Si ${ }^{1, *}$, Haijin Zhou ${ }^{1}$, Taiping Yang ${ }^{1}$, Dongshang Yang ${ }^{1}$ and Liang Xi ${ }^{1}$ \\ 1 Key Laboratory of Environmental Optics and Technology, Anhui Institute of Optics and Fine Mechanics, \\ Hefei Institutes of Physical Science, Chinese Academy of Sciences, Hefei 230031, China; \\ yyqian@aiofm.ac.cn (Y.Q.); yhluo@aiofm.ac.cn (Y.L.); hjzhou@aiofm.ac.cn (H.Z.); tpyang@aiofm.ac.cn (T.Y.); \\ dsyang@aiofm.ac.cn (D.Y.); 1xi@aiofm.ac.cn (L.X.) \\ 2 University of Science and Technology of China, Hefei 230026, China \\ * Correspondence: sifuqi@aiofm.ac.cn \\ + Primary first authors.
}

Citation: Qian, Y.; Luo, Y.; Si, F.; Zhou, H.; Yang, T.; Yang, D.; Xi, L. Total Ozone Columns from the Environmental Trace Gases Monitoring Instrument (EMI) Using the DOAS Method. Remote Sens. 2021 13, 2098. https://doi.org/10.3390/ rs13112098

Academic Editor: Daniele Bortoli

Received: 28 April 2021

Accepted: 25 May 2021

Published: 27 May 2021

Publisher's Note: MDPI stays neutral with regard to jurisdictional claims in published maps and institutional affiliations.

Copyright: (c) 2021 by the authors. Licensee MDPI, Basel, Switzerland. This article is an open access article distributed under the terms and conditions of the Creative Commons Attribution (CC BY) license (https:// creativecommons.org/licenses/by/ $4.0 /)$

\begin{abstract}
Global measurements of total ozone are necessary to evaluate ozone hole recovery above Antarctica. The Environmental Trace Gases Monitoring Instrument (EMI) onboard GaoFen 5, launched in May 2018, was developed to measure and monitor the global total ozone column (TOC) and distributions of other trace gases. In this study, some of the first global TOC results of the EMI using the differential optical absorption spectroscopy (DOAS) method and validation with ground-based TOC measurements and data derived from Ozone Monitoring Instrument (OMI) and TROPOspheric Monitoring Instrument (TROPOMI) observations are presented. Results show that monthly average EMI TOC data had a similar spatial distribution and a high correlation coefficient $(\mathrm{R} \geq 0.99)$ with both OMI and TROPOMI TOC. Comparisons with ground-based measurements from the World Ozone and Ultraviolet Radiation Data Centre also revealed strong correlations $(\mathrm{R}>0.9)$. Continuous zenith sky measurements from zenith scattered light differential optical absorption spectroscopy instruments in Antarctica were also used for validation $(R=0.9)$. The EMI-derived observations were able to account for the rapid change in TOC associated with the sudden stratospheric warming event in October 2019; monthly average TOC in October 2019 was 45\% higher compared to October 2018. These results indicate that EMI TOC derived using the DOAS method is reliable and has the potential to be used for global TOC monitoring.
\end{abstract}

Keywords: GaoFen 5; Environmental Trace Gases Monitoring Instrument; total ozone column; DOAS; ozone hole

\section{Introduction}

Stratospheric ozone, distributed at an altitude of approximately $20-35 \mathrm{~km}$, plays an important role in protecting human health and the Earth's ecological balance [1,2] by providing a shield against strong UV radiation $(200-300 \mathrm{~nm})$ [3]. Stratospheric ozone is involved in numerous photochemical reactions, especially the activation of $\mathrm{Br}$ and $\mathrm{Cl}$, which can destroy the ozone layer [4,5]. The hole in the ozone layer was first found by Farman in the Argentine Islands $\left(65^{\circ} \mathrm{S}, 64^{\circ} \mathrm{W}\right)$ and Halley Bay $\left(76^{\circ} \mathrm{S}, 27^{\circ} \mathrm{W}\right)$ [6]. Chlorofluorocarbons (CFCs), a leading cause of ozone depletion, were phased out by the Montreal Protocol [7], and in response, the total ozone column (TOC) above Antarctica is recovering and the ozone hole is reducing [8-10].

In the past 30 years, satellite observations have been widely applied to retrieve the TOC by measuring backscattered light using the nadir viewing method [11-13]. Satelliteborne instruments with a high spatial resolution can obtain more accurate information on regional trace gases, which have facilitated research in atmospheric chemistry, including ozone hole monitoring and the analysis of stratospheric dynamics [11]. The Global Ozone Monitoring Experiment (GOME) onboard the European Remote Sensing-2 satellite was 
launched in 1995 [14] with a fitting window of 325-335 nm for the retrieval of GOME TOC at a spatial resolution of $320 \times 40 \mathrm{~km}^{2}$. The second-generation sensor, GOME-2, was launched in 2006 and has an improved spatial resolution of $80 \times 40 \mathrm{~km}^{2}$ [15]. Furthermore, the SCanning Imaging Absorption spectroMeter for Atmospheric CHartographY (SCIAMACHY) instrument, onboard the Environmental Satellite launched in 2002, can retrieve the TOC and stratospheric ozone profiles using nadir and limb viewing geometries at a spatial resolution of $60 \times 30 \mathrm{~km}^{2}$ [16]. With a spatial resolution of $50 \mathrm{~km}$ (nadir), the ultraviolet total ozone unit onboard the FY-3 satellite (launched in 2008) was the first Chinese instrument used for the daily monitoring of global total ozone [17]. The spatial resolution of the Ozone Monitoring Instrument (OMI; $13 \times 24 \mathrm{~km}^{2}$ ) enables the retrieval of regional air pollutants [18], while the spatial resolution of the TROPOspheric Monitoring Instrument (TROPOMI; up to $3.5 \times 5.5 \mathrm{~km}^{2}$ ) provides even more accurate information on regional pollutant gases [19]. The Environmental Trace Gases Monitoring Instrument (EMI) onboard the GaoFen 5 (GF-5) satellite was launched on 9 May 2018 and is the first Chinese UV-Vis hyperspectral satellite-borne spectrometer. The EMI is used to monitor and analyze air pollution and atmospheric chemistry at a spatial resolution (nadir) of $13 \times 12 \mathrm{~km}^{2}$.

Differential optical absorption spectroscopy (DOAS) [20] has been widely used for the retrieval of TOC. The GOME Data Processor (GDP) version 4.4 retrieval algorithm, which employs the two-step DOAS method (slant column density (SCD) and air mass factor (AMF) retrieval), is an upgraded version of the GDP 4.0 algorithm used to retrieve the TOC from GOME-2 [12]. The TOC from OMI is determined using a three-step DOAS method; SCD retrieval, AMF retrieval, and cloud correction [21]. The TROPOMI near real-time and offline TOC products use the updated GDP 4.x and GOME-type Direct FITting (GODFIT) $\mathrm{v} 4$ algorithm respectively [13]. TOC retrieval from the EMI is determined using a two-step DOAS method. First, DOAS fitting is performed to obtain the ozone SCD. Then the AMF, needed to convert SCD to vertical column density (VCD), is calculated using the solar zenith angle (SZA), solar azimuth angle (SAA), viewing azimuth angle (VAA), viewing zenith angle (VZA), albedo, latitude, month, VCD, and cloud information. Cloud correction in the EMI TOC algorithm is also considered in the AMF calculations.

The aim of this study is to validate TOC retrieval from the EMI using the DOAS method. Reliable ground-based (GB) TOC data are needed to estimate the quality of satellite TOC products and improve the satellite TOC retrieval algorithm. We compared 1.5 years of EMI TOC observations with seven GB station measurements from the WOUDC database. Then, we compared monthly averaged EMI TOC in October 2018 with TOCs from OMI and TROPOMI. Finally, we validated EMI TOC using Zenith Scattered Light-Differential Optical Absorption Spectroscopy (ZSL-DOAS) observations from a GB instrument. Our validations confirmed that TOC retrieval from EMI using the DOAS method is reliable.

\section{Data}

\subsection{EMI Data}

The GF- 5 satellite, at an altitude of $705 \mathrm{~km}$, is part of the Chinese high-resolution Earth observation system and has an ascending equator cross time of 13:30 local standard time (LST) $[22,23]$. The ultraviolet (UV) and visible (VIS) wavelength bands for the EMI are UV1 (240-315 nm), UV2 (311-403 nm), VIS1 (401-550 nm), and VIS2 (545-710 nm) [24]. In this study, we used the UV2 band to retrieve EMI TOC. The wide field of view (FOV) of the EMI $\left(114^{\circ}\right)$ ensures daily global coverage. Each channel has two-dimensional charge-coupled device (CCD) detectors, with a spectral resolution of $0.3-0.5 \mathrm{~nm}$. The EMI scanning method is shown in Figure 1. 


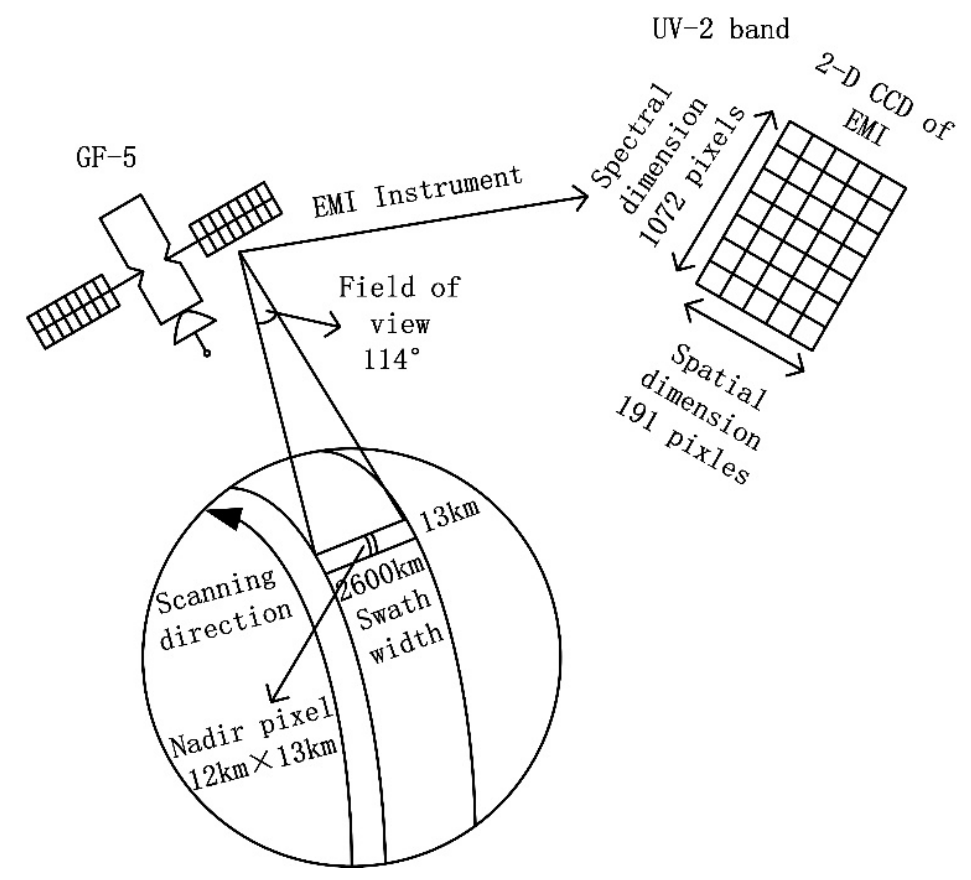

Figure 1. Diagram showing the nadir scanning method used by the Environmental Trace Gases Monitoring Instrument (EMI).

\subsection{Auxiliary Data}

\subsubsection{Satellite Data}

The OMI is onboard the EOS Aura satellite, launched on 15 July 2004, with an overpass time of 13:30 LST. The OMI FOV can reach $114^{\circ}$, providing daily global coverage, and TOC can be retrieved using both UV (270-380 $\mathrm{nm})$ and VIS (350-500 nm) wavelengths [25]. The nadir spatial resolution of OMI is $13 \times 14 \mathrm{~km}^{2}$, with a spectral resolution of $0.5 \mathrm{~nm}$, and TOC data are available at https: / / disc.gsfc.nasa.gov/datasets/OMDOAO3_003/summary (accessed on 1 January 2021).

TROPOMI is onboard the Copernicus Sentinel-5 Precursor (S5P) satellite, launched in October 2017, with an overpass time of 13:30 LST. TROPOMI has a nadir pixel size of $3.5 \times 5.5 \mathrm{~km}^{2}[13,26]$, daily coverage with approximately 14 orbits per day, and a spectral resolution of $0.25-1 \mathrm{~nm}$. Spectral bands cover UV-Vis $(270-550 \mathrm{~nm})$, NIR $(675-775 \mathrm{~nm})$, and SWIR (2305-2385 nm) [19], and TOC data are available at https:/ / s5phub.copernicus.eu/ dhus/\#/home (accessed on 7 January 2021). The detailed instrument performances of EMI, OMI, and TROPOMI are shown in Table 1.

Table 1. Summary of the Environmental Trace Gases Monitoring Instrument (EMI), Ozone Monitoring Instrument (OMI), and TROPOspheric Monitoring Instrument (TROPOMI).

\begin{tabular}{cccc}
\hline Parameter & EMI & OMI & TROPOMI \\
\hline Detection wavelength & $240-710 \mathrm{~nm}$ & $270-500 \mathrm{~nm}$ & $0.5 \mathrm{~nm}$ \\
Spectral resolution & $0.3-0.5 \mathrm{~nm}$ & $13 \times 24 \mathrm{~km}^{2}$ & $270-550,675-775$, and 230-2385 nm \\
Spatial resolution (nadir) & $12 \times 13 \mathrm{~km}^{2}$ & $114^{\circ}$ & $0.225-0.65 \mathrm{~nm}$ \\
Field of view & $114^{\circ}$ & $705 \mathrm{~km}$ & $3.5 \times 5.5 \mathrm{~km}^{2}$ \\
Flight height & $705 \mathrm{~km}$ & $331.1-336.1 \mathrm{~nm}$ & $108^{\circ}$ \\
Fitting window & $313-320 \mathrm{~nm}$ & Doubling-Adding- & Vector Linearized Discrete Ordinate \\
for TOC product & & KNMI (DAK) & Radiative Transfer (VLIDORT) \\
Radiative transfer model & SCIATRAN & & $325-335 \mathrm{~nm}$ \\
for AMF calculation & &
\end{tabular}




\subsubsection{Ground-Based Data}

The WOUDC database (http:/ / woudc.org, accessed on 20 December 2020) provides systematic GB measurements of TOC on a global scale [3]. Daily averaged TOC values or representative TOC values were submitted to the WOUDC by contributors [27] and we used TOC measurements from Brewer and Dobson in this study due to their reliability. Furthermore, ZSL-DOAS observations (http:/ / www.ndaccdemo.org/, accessed on 26 December 2020) from the Système d'Analysepar Observation Zénitale (SAOZ) network were also used for validation. Two TOC values in the morning and afternoon can be retrieved using the ZSL-DOAS method from the GB measurements of the SAOZ network.

\section{TOC Retrieval Algorithm}

\subsection{SCD Retrieval}

The DOAS method, based on the Lambert-Beer law, retrieves the concentrations of interest trace gases through their characteristic absorptions and the measured intensity. From the Lambert-Beer law and derivation:

$$
\ln \frac{I^{*}(\lambda)}{I_{o}(\lambda)}=\sum\left(\sigma_{i}^{*}(\lambda) \cdot c_{i} \cdot L\right)=\sum\left(\sigma_{i}^{*}(\lambda) \cdot \mathrm{SCD}_{i}\right)
$$

where $I^{*}(\lambda)$ means the measured intensity, $I_{o}(\lambda)$ means the original luminous intensity, $\sigma_{i}^{*}$ means the cross section of trace gas $i, c_{i}$ means the averaged concentration of trace gas $i$, $L$ means the length of optical path, $\mathrm{SCD}_{i}$ means the slant columns density of trace gas $i$, $\ln \frac{I^{*}(\lambda)}{I_{o}(\lambda)}$ means the differential optical density, and $\lambda$ means the wavelength. The SCDs of desired trace gases can be retrieved by least-squares fitting from Equation (1).

Ozone SCDs were retrieved using QDOAS software developed by the Royal Belgian Institute for Space Aeronomy (BIRA-IASB) (http:/ / uv-vis.aeronomie.be/software/QDOAS/, accessed on 20 October 2020), with a retrieval wavelength range of $313-320 \mathrm{~nm}$. Solar irradiance measured on 12 June 2018 was used as the reference spectrum. We note that a fitting window of $325-335 \mathrm{~nm}$ is more appropriate for ozone SCDs; however, owing to the limitations of the instrument and reference spectrum, the results of ozone SCDs in the 325-335 nm fitting window were not satisfactory. Therefore, we chose the 313-320 nm fitting window to retrieve ozone SCDs from the EMI. This lower wavelength may lead to larger AMF biases when the SZA is large.

$\mathrm{O}_{3}, \mathrm{NO}_{2}, \mathrm{HCHO}, \mathrm{BrO}, \mathrm{SO}_{2}$, and ring cross-sections (the rotational Raman scattering effect, calculated by Ring.exe of QDOAS) were considered in the retrieval algorithm, and the detailed parameters are listed in Table 2. From the Algorithm Theoretical Basis Document (ATBD) of TROPOMI ozone product (https:/ / sentinels.copernicus.eu/documents / 247904/2476257/Sentinel-5P-TROPOMI-ATBD-Total-Ozone, accessed on 18 May 2021), a difference of $1-2 \%$ appeared when using the cross-sections with different temperatures.

Table 2. Fitting parameter settings for ozone slant column density (SCD) retrieval.

\begin{tabular}{cc}
\hline Parameter & Settings \\
\hline Fitting Interval & $313-320 \mathrm{~nm}$ \\
Polynomial & Order 4 \\
\hline Cross-sections & \\
$\mathrm{O}_{3}$ & $223 \mathrm{~K}, 243 \mathrm{~K},[28]$ \\
$\mathrm{NO}_{2}$ & $298 \mathrm{~K},[29]$ \\
$\mathrm{SO}_{2}$ & $298 \mathrm{~K},[30]$ \\
$\mathrm{BrO}$ & $223 \mathrm{~K},[31]$ \\
$\mathrm{HCHO}$ & $297 \mathrm{~K},[32]$ \\
Ring & Calculated using QDOAS \\
\hline
\end{tabular}

Figure 2 shows an example of the fitting results carried out with the QDOAS tool for one orbit (orbit number 002590) on 2 November 2018. For panel (a), in red is de- 
picted the reference spectrum while the black curve represents the measured spectrum. Panels (b)-(h) show the differential cross-sections (black curves) included in the analysis and fitting functions (in red). Panel (i) depicts the residual of the DOAS fitting. From Figure 2, the retrieved ozone SCD and SCD error were $1.515 \times 10^{19}$ molecule $/ \mathrm{cm}^{2}$ and $1.334 \times 10^{17}$ molecule $/ \mathrm{cm}^{2}$, respectively, with the root mean square (RMS) of the spectral fitting residual of $1.909 \times 10^{-3}$. Therefore, the relative SCD error, calculated by $\mathrm{SCD}_{\text {error }} / \mathrm{SCD}$, was $0.88 \%$.

(a)

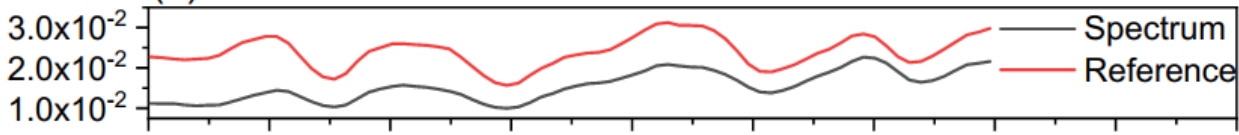

(b)

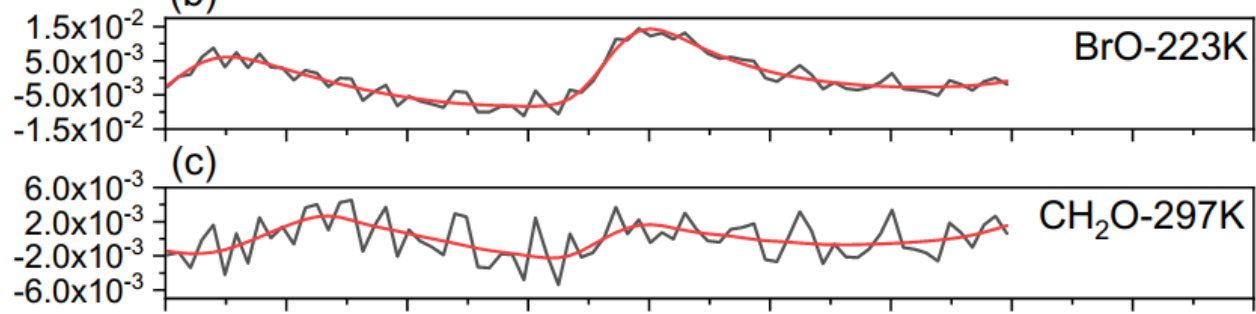

(d)

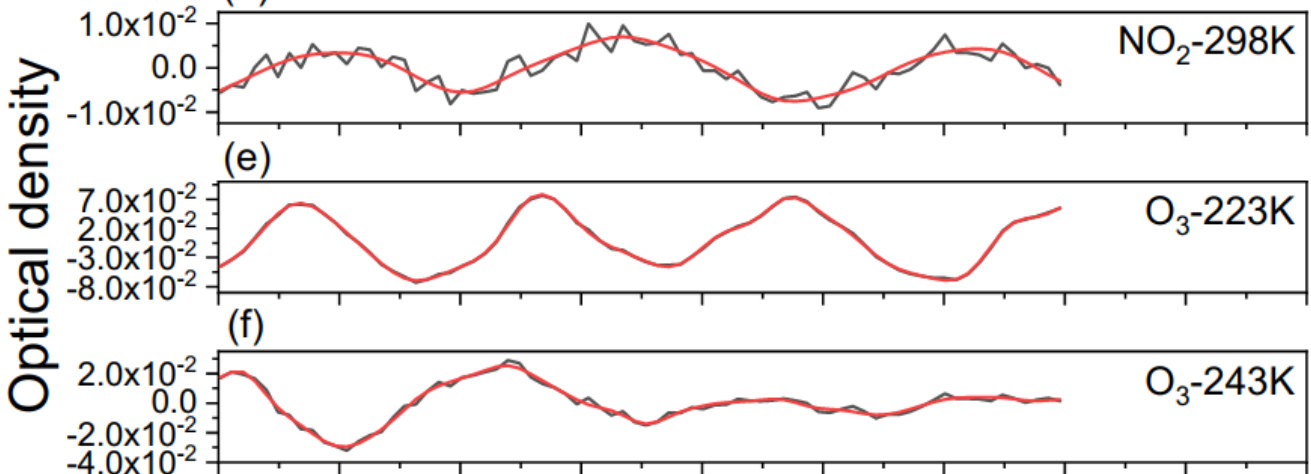

(g)
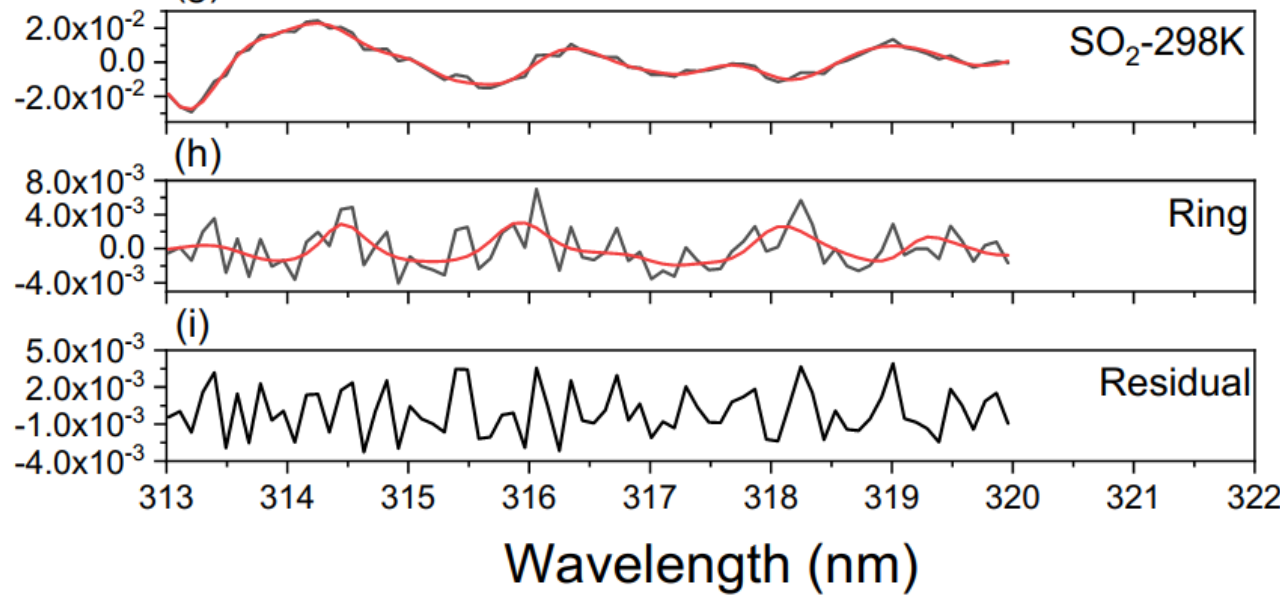

Figure 2. An example of ozone slant column density (SCD) retrieval from EMI on 2 November 2018 showing the (a) measured (black line) and reference spectrum (red line), (b) measured (black line) and fitted (red line) BrO optical density, (c) measured (black line) and fitted (red line) $\mathrm{CH}_{2} \mathrm{O}$ optical density, (d) measured (black line) and fitted (red line) $\mathrm{NO}_{2}$ optical density, (e) measured (black line) and fitted (red line) $\mathrm{O}_{3}\left(223 \mathrm{~K}\right.$ ) optical density, (f) measured (black line) and fitted (red line) $\mathrm{O}_{3}$ (243 K) optical density, (g) measured (black line) and fitted (red line) $\mathrm{SO}_{2}$ optical density, (h) measured (black line) and fitted (red line) ring optical density, and (i) the remaining residuals of differential optical absorption spectroscopy (DOAS) fitting. 


\subsection{AMF Retrieval}

The AMF, calculated by the SCIATRAN radiative transfer model, was used to convert the SCD to VCD. In this study, the AMF was determined using multidimensional linear interpolation from a precalculated AMF lookup table (LUT), and $316.3 \mathrm{~nm}$ was used to establish the AMF LUT. The parameter nodes for the establishment of the AMF LUT are listed in Table 3. In this study, column- and latitude-dependent profiles were used as a priori profiles to reduce the uncertainty of the AMF calculation caused by variations in ozone profiles. The a priori profiles were obtained from the TOMS V8 climatology [33]. Figure 3 shows the dependence of AMF on the ozone profiles with different VCDs. It is apparent that ozone profiles have a large influence on the AMF calculation, especially when the SZA is large-ozone profiles can cause $20 \%$ differences in the AMF when the SZA is $75^{\circ}$. Hence, the appropriate ozone profiles should be selected using precalculated VCDs to reduce the uncertainty of the AMF calculation. The AMF of the EMI TOC was determined using a two-step AMF calculation method. First, the precalculated VCDs were obtained through SCDs and AMFs, which were determined using multidimensional linear interpolation from the precalculated rough AMF LUT (without the parameter node of VCD), and the ozone profiles used for rough AMF LUT were selected by month and latitude from the SCIATRAN database. Then, the accurate AMFs were calculated by multidimensional linear interpolation from the precalculated accurate AMF LUT. The VCD, SZA, relative azimuth angle (RAA), VZA, surface albedo, latitude, month, and cloud pressure were the parameter nodes of the accurate AMF LUT. To reduce uncertainties in the AMF calculations, we only used data with SZAs less than $82^{\circ}$ in this study. The surface albedo was obtained from the OMLER monthly climatology derived from several years of OMI observations, with a resolution of $0.5^{\circ} \times 0.5^{\circ}$ (lat $\times$ lon) [34].

Table 3. The parameter node settings of the air mass factor (AMF) lookup table (LUT).

\begin{tabular}{|c|c|c|}
\hline Parameter & Number of Nodes & Values \\
\hline $\operatorname{SZA}\left({ }^{\circ}\right)$ & 18 & $\begin{array}{l}0,10,20,30,35,40,45,50,55 \\
60,65,70,72,74,76,78,80,82\end{array}$ \\
\hline $\operatorname{RAA}\left(^{\circ}\right)$ & 5 & $0,45,90,135,180$ \\
\hline $\operatorname{VZA}\left({ }^{\circ}\right)$ & 13 & $\begin{array}{c}0,5,10,15,20,25,30,35,40 \\
45,50,55,60\end{array}$ \\
\hline Latitude $\left({ }^{\circ}\right)$ & 18 & $\begin{array}{c}-85,-75,-65,-55,-45 \\
-35,-25,-15,-5,5,15,25 \\
35,45,55,65,75,85\end{array}$ \\
\hline Albedo & 9 & $\begin{array}{c}0,0.05,0.1,0.20,0.30,0.40 \\
0.60,0.80,1.0\end{array}$ \\
\hline Cloud pressure $(\mathrm{hPa})$ & 9 & $\begin{array}{c}1013,795,701,616,472,356 \\
264,164,96\end{array}$ \\
\hline Month & 12 & $1,2,3,4,5,6,7,8,9,10,11,12$ \\
\hline VCD (DU) for AMF correction & 10 & $\begin{array}{c}125,175,225,275,325,375 \\
425,475,525,575\end{array}$ \\
\hline
\end{tabular}

The effects of clouds, which are related to the calculation of the AMF, should be considered when a ground pixel is covered by clouds. The cloud information (cloud pressure and cloud fraction) used for the AMF calculation of EMI TOC was obtained from the TROPOMI cloud product (S5P_L2_CLOUD_1 and S5P_L2_CLOUD_HiR1), with a resampled spatial resolution of $0.25^{\circ} \times 0.25^{\circ}$ (lat $\times$ lon). The independent pixel approximation method was used to calculate the AMF by splitting the partly cloudy ground pixels into a weighted sum for clear $\left(\mathrm{M}_{\text {clear }}\right)$ and cloudy conditions $\left(\mathrm{M}_{\text {cloud }}\right)$ :

$$
M=w \cdot M_{\text {cloudy }}+(1-w) \cdot M_{\text {clear }}
$$

where $w$ denotes the weight, namely the effective cloud fraction obtained from TROPOMI. 


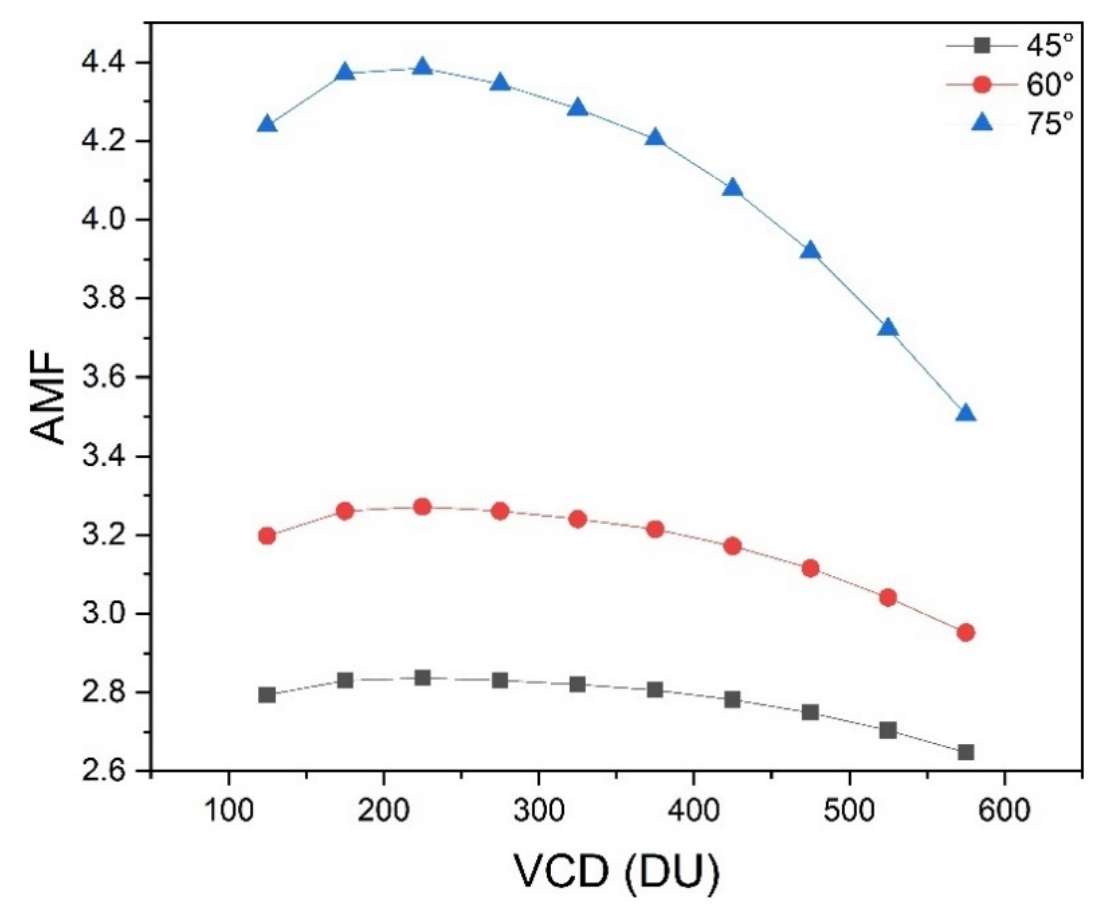

Figure 3. The dependence of the air mass factor (AMF) on ozone a priori profiles with different vertical column densities (VCDs), at solar zenith angles (SZAs) of $45^{\circ}, 60^{\circ}$, and $75^{\circ}$. The viewing zenith angle (VZA), relative azimuth angle (RAA), and albedo are $45^{\circ}, 60^{\circ}$ and 0.3 , respectively.

\subsection{De-Stripe}

Obvious stripes, due to irradiance calibration error, in the EMI TOC retrieval (Figure 4a) needed to be removed before validation, and we used spatial filtering following the Fourier transform method to remove the stripes following Boersma's method [35]. Taking the TOC retrieval of one orbit on 2 November 2018 as an example, the steps are as follows:

1. Determine the window (191 across track by 50 along track pixels) with the minimum variance of TOC.

2. Calculate the average TOC in the along-track direction, giving 191 average TOC values.

3. Obtain the lowest frequency term and high-frequency terms (except the lowest frequency term) using Fourier transformation from 191 averaged values. The 191 highfrequency terms are correction values, which are considered to be noise.

4. Perform the stripe correction by subtracting the correction values in step 3 .
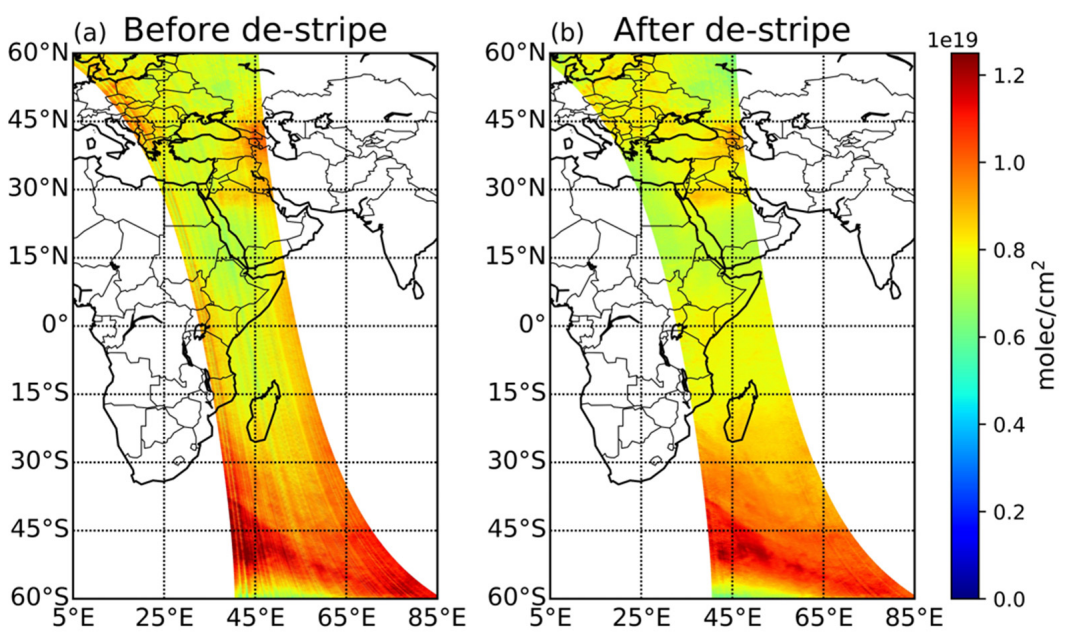

Figure 4. The retrieved total ozone columns (TOCs) from EMI before (a) and after (b) de-striping. 
The TOC following de-striping is shown in Figure $4 \mathrm{~b}$.

\subsection{Error Analysis}

In this study, we did not consider systematic errors because they have a limited influence on trends [11]. The relative SCD error of the EMI TOC retrieval algorithm was less than $2 \%$. The relative error of a priori ozone profiles on the AMF, which have a large influence on AMF calculations, were evaluated through extensive comparisons with a year of ozonesonde data from the WOUDC database on a global scale. The detailed error sources and relative errors are listed in Table 4 . The total error of the EMI TOC, calculated using $E_{\mathrm{VCD}}=\sqrt{\left(E_{\mathrm{SCD}}^{2}+E_{\text {albedo }}^{2}+E_{\text {aerosol }}^{2}+E_{\text {cloud_pressure }}^{2}+E_{\text {cloud_fraction }}^{2}+E_{\text {profile }}^{2}\right)}$, was less than $4.5 \%$ (excluding systematic errors).

Table 4. Detailed error sources and their relative errors.

\begin{tabular}{cc}
\hline Error Sources & Relative Error (\%) \\
\hline Aerosols & 0.8 \\
Albedo & 0.3 \\
Cloud pressure & $<1.5$ \\
Cloud fraction & $<0.5$ \\
SCD & $<2$ \\
Ozone profiles & $<3.0\left(\mathrm{SZA}<80^{\circ}\right)$ \\
& $<3.6\left(\mathrm{SZA}<82^{\circ}\right)$ \\
\hline
\end{tabular}

\section{Results and Validations}

\subsection{EMI Versus OMI and TROPOMI}

Global TOCs in October 2018 from EMI, TROPOMI, and OMI are shown in Figure 5a,c,e, at a resampled spatial resolution of $0.25^{\circ} \times 0.5^{\circ}($ lat $\times$ lon). Figure $5 \mathrm{~b}$ shows that the relative SCD error was less than $2 \%$. The relative differences in EMI from TROPOMI and OMI, calculated using $100 \% \times \frac{\mathrm{VCD}_{\mathrm{TROPOMI}}-\mathrm{VCD}_{\mathrm{EMI}}}{\mathrm{VCD}_{\mathrm{EMI}}}$ and $100 \% \times \frac{\mathrm{VCD}_{\mathrm{OMI}}-\mathrm{VCD}_{\mathrm{EMI}}}{\mathrm{VCD}_{\mathrm{EMI}}}$, are shown in Figure $5 \mathrm{~d}$,f. It is apparent that global TOC retrieved from EMI shows a similar spatial distribution to OMI and TROPOMI. High ozone values are concentrated between $30-60^{\circ} \mathrm{S}$, and low values are apparent in the high-latitude region of Antarctica. The relative differences between EMI and TROPOMI ranged from $0.27-0.29 \%$ (at a 99\% confidence interval), with an average absolute difference of $0.28 \%$, which was calculated using $100 \% \times \frac{1}{N} \sum\left|\frac{\mathrm{VCD}_{\mathrm{TROPOMI}}-\mathrm{VCD}_{\mathrm{EMI}}}{\mathrm{VCD}_{\mathrm{EMI}}}\right|$. As shown in Figure 5d,f, EMI TOC shows a 10\% difference compared with TROPOMI and OMI in some high-latitude areas, where the SZAs are large. As mentioned in Section 3.1, larger biases are likely in the AMF calculation when the SZA is large, and we attribute the large biases of EMI TOC in some high-latitude areas to this. Furthermore, the distribution of snow and ice may influence the retrieval of TOC [12], and we will consider these parameters in future research. Additional results for global TOCs from EMI, OMI, and TROPOMI and their relative differences are provided in the Appendix A (Figures A1 and A2). Our results show that the EMI TOC is highly consistent with the OMI and TROPOMI TOCs.

The linear fitting of global TOC between EMI and OMI and TROPOMI in October 2018 are shown in Figure 6a,b. Regression analysis shows that the EMI TOC has a good correlation with both OMI and TROPOMI, with Pearson's correlation coefficients (R) of 0.99 for both. The root mean square errors (RMSEs) between EMI TOC and OMI and TROPOMI TOCs, calculated using $\sqrt{\frac{\sum\left(\mathrm{VCD}_{\mathrm{OMI}}-\mathrm{VCD}_{\mathrm{EMI}}\right)^{2}}{\mathrm{~N}}}$ and $\sqrt{\frac{\sum\left(\mathrm{VCD}_{\mathrm{TROPOMI}}-\mathrm{VCD}_{\mathrm{EMI}}\right)^{2}}{\mathrm{~N}}}$, were 9.9 and $8.4 \mathrm{DU}$, respectively. The root mean square relative errors (RMSREs), calculated using $100 \% \times \sqrt{\frac{1}{\mathrm{~N}} \sum\left(\frac{\mathrm{VCD}_{\mathrm{OMI}}-\mathrm{VCD}_{\mathrm{EMI}}}{\mathrm{VCD}_{\mathrm{EMI}}}\right)^{2}}$ and $100 \% \times \sqrt{\frac{1}{\mathrm{~N}} \sum\left(\frac{\mathrm{VCD}_{\mathrm{TROPOMI}}-\mathrm{VCD}_{\mathrm{EMI}}}{\mathrm{VCD}_{\mathrm{EMI}}}\right)^{2}}$, were 3.6 and $3.2 \%$, respectively. 

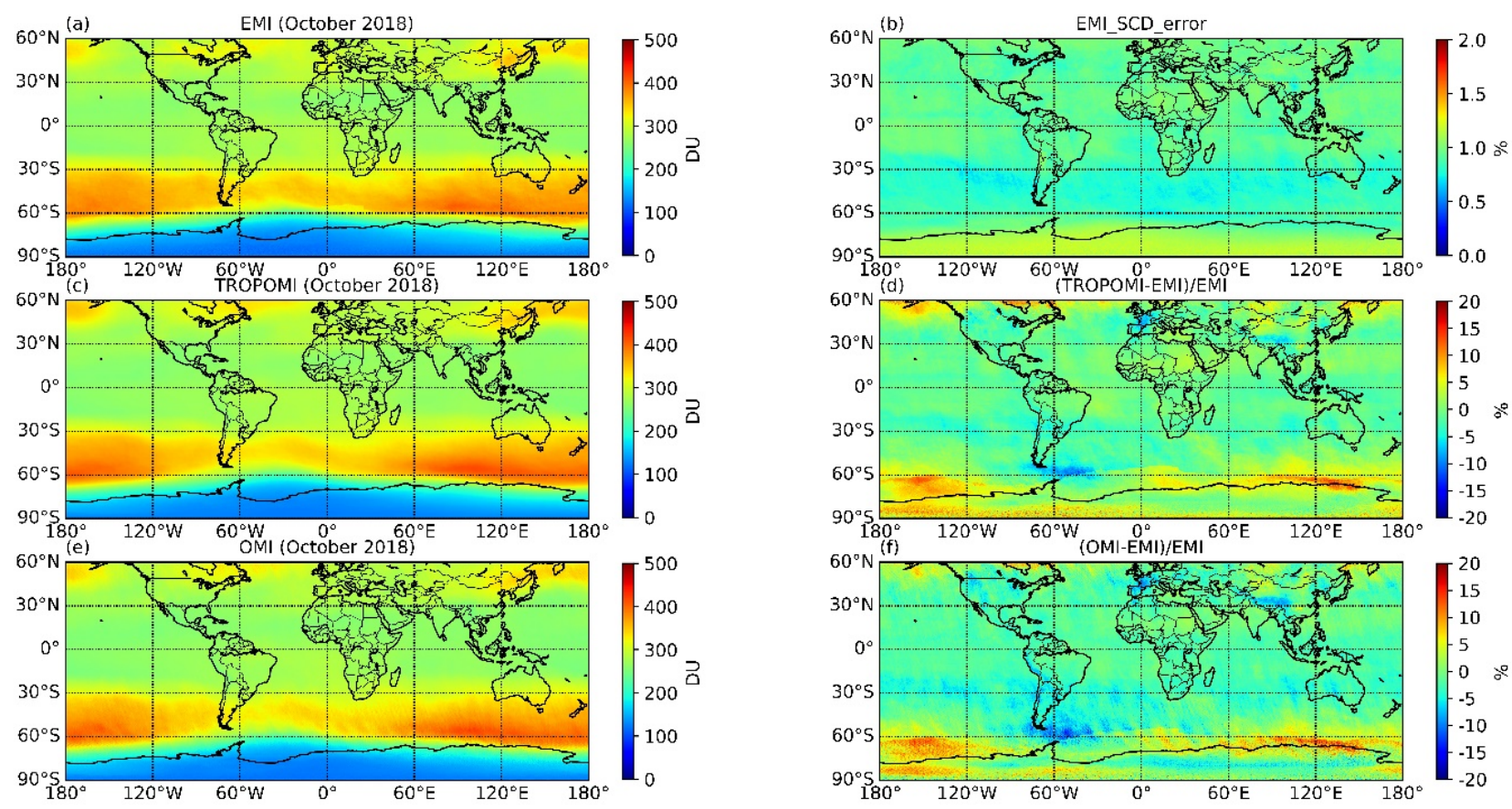

Figure 5. Spatial distribution of (a) monthly average EMI TOC, (b) EMI relative monthly average SCD error, (c) monthly average TROPOspheric Monitoring Instrument (TROPOMI) TOC, (d) average relative difference between EMI and TROPOMI, (e) monthly average Ozone Monitoring Instrument (OMI) TOC, and (f) average relative difference between EMI and OMI for October 2018.
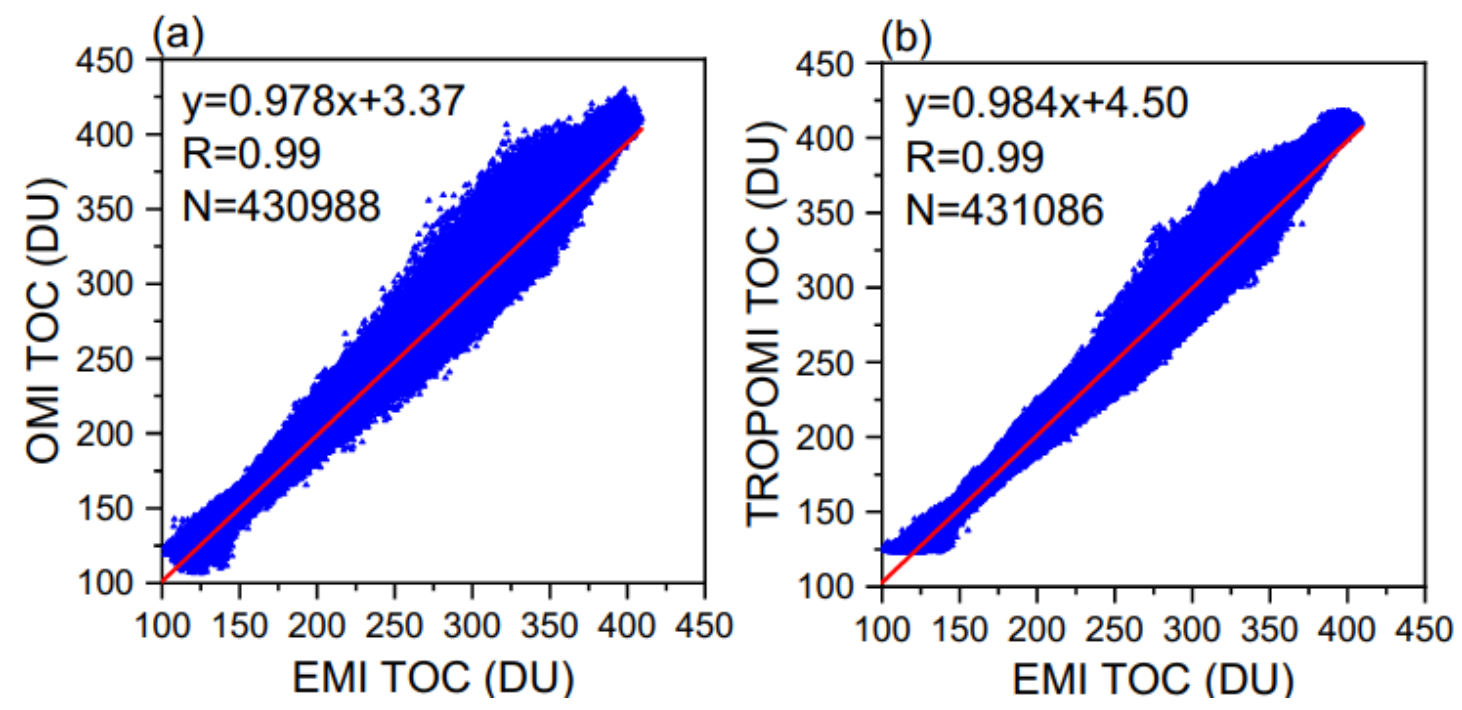

Figure 6. Linear fitting of EMI TOC with (a) OMI TOC and (b) TROPOMI TOC.

\subsection{EMI Versus GB Measurements}

Seven GB measurements from the WOUDC database were used to validate the EMI TOC, and a summary of these stations is shown in Table 5. Daily average TOCs with error bars from the EMI and GB measurements are shown in Figure 7. The EMI TOC used for comparison with GB measurements was the daily average value within the ground pixel $\left(1^{\circ} \times 1^{\circ}\right)$ of the corresponding GB station. The average absolute difference (at a 95\% confidence interval) between the EMI and GB measurements at these stations was less than $5.5 \%$ (Table 5). Figure 7 shows that the daily average EMI TOC agrees well with the GB measurements; however, the EMI TOC is higher than the GB measurements when TOC 
was located at a high level. The regression analyses of EMI TOC with measurements from the GB stations are shown in Figure 8. The $\mathrm{R}$ is greater than 0.92 at all stations.

Table 5. Summary information for the selected ground-based TOC monitoring stations.

\begin{tabular}{|c|c|c|c|c|c|}
\hline Station & Latitude, Longitude & Method & $\begin{array}{c}\text { Averaged } \\
\text { Difference (95\% } \\
\text { Confidence Interval) }\end{array}$ & $\begin{array}{l}\text { Number of } \\
\text { Measurement } \\
\text { Days }\end{array}$ & $\begin{array}{c}\text { Root Mean } \\
\text { Square Relative } \\
\text { Error (RMSRE) }\end{array}$ \\
\hline $\begin{array}{c}\text { Hohenpeissenberg, } \\
\text { Germany }\end{array}$ & $47.80^{\circ} \mathrm{N}, 11.02^{\circ} \mathrm{E}$ & Brewer & $3.30 \%$ & 281 & $4.4 \%$ \\
\hline $\begin{array}{l}\text { Observatoire de Haute } \\
\text { Provence, France }\end{array}$ & $43.94^{\circ} \mathrm{N}, 5.71^{\circ} \mathrm{E}$ & SAOZ & $3.02 \%$ & 284 & $4.1 \%$ \\
\hline $\begin{array}{l}\text { Boulder, CO, } \\
\text { United States }\end{array}$ & $39.99^{\circ} \mathrm{N}, 105.26^{\circ} \mathrm{W}$ & Dobson & $2.97 \%$ & 300 & $4.0 \%$ \\
\hline Brisbane, Australia & $27.39^{\circ} \mathrm{S}, 153.13^{\circ} \mathrm{E}$ & Dobson & $2.10 \%$ & 329 & $2.8 \%$ \\
\hline Melbourne, Australia & $37.81^{\circ} \mathrm{S}, 144.97^{\circ} \mathrm{E}$ & Dobson & $3.34 \%$ & 299 & $4.3 \%$ \\
\hline Rio Gallegos, Argentina & $51.60^{\circ} \mathrm{S}, 69.32^{\circ} \mathrm{W}$ & SAOZ & $4.13 \%$ & 247 & $5.3 \%$ \\
\hline $\begin{array}{c}\text { Concordia Dome C, } \\
\text { Antarctica }\end{array}$ & $75.10^{\circ} \mathrm{S}, 123.35^{\circ} \mathrm{E}$ & SAOZ & $5.47 \%$ & 129 & $9.0 \%$ \\
\hline
\end{tabular}
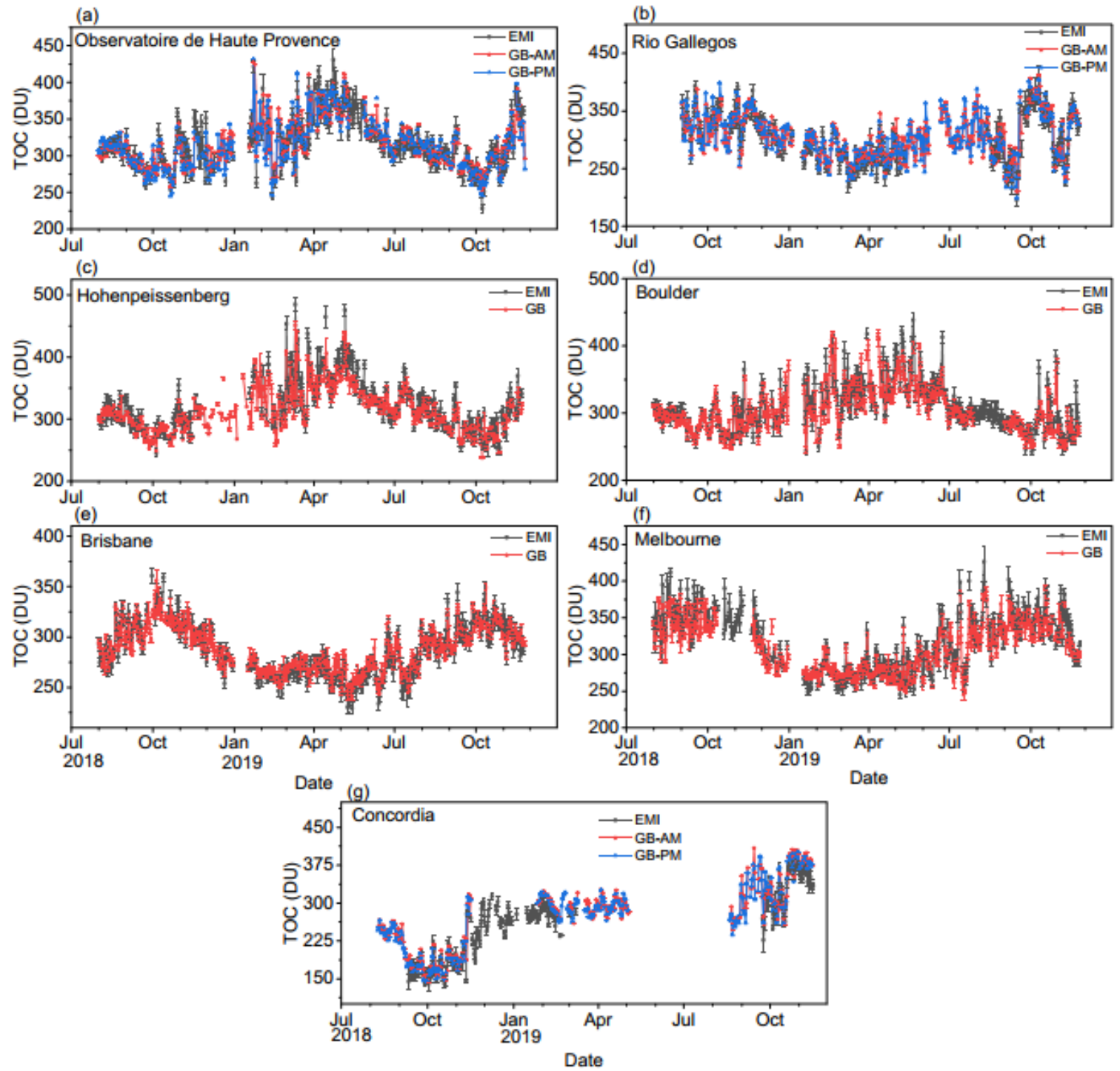

Figure 7. Daily average TOCs from EMI observations and ground-based (GB) observations at the Observatoire de Haute Provence (a), Rio Gallegos (b), Hohenpeissenberg (c), Boulder (d), Brisbane (e), Melbourne (f), and Concordia (g) stations. 

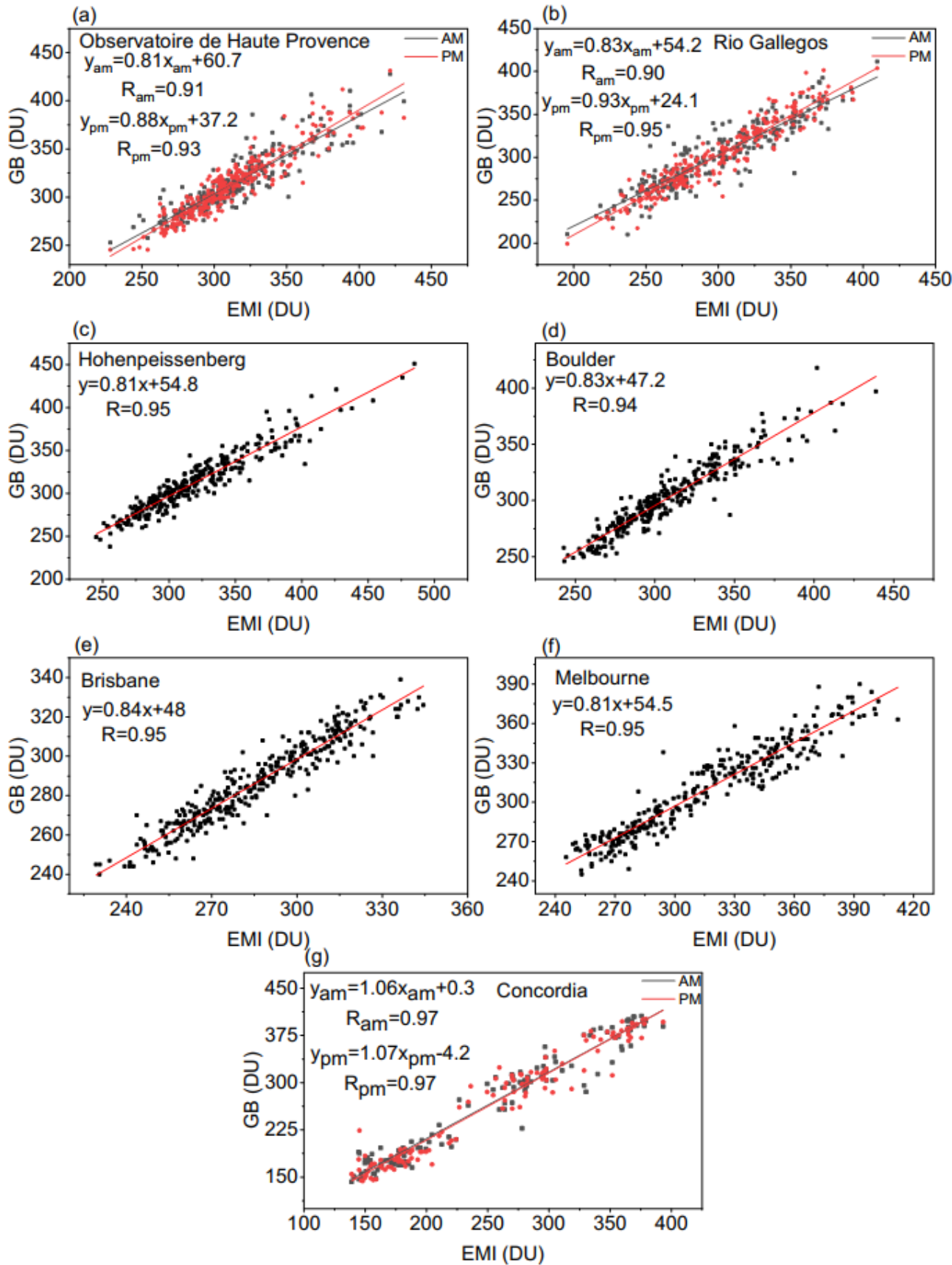

Figure 8. Linear fitting of EMI TOC and GB observations at the Observatoire de Haute Provence (a), Rio Gallegos (b), Hohenpeissenberg (c), Boulder (d), Brisbane (e), Melbourne (f), and Concordia (g) stations.

\subsection{Application Case}

We compared daily TOCs from EMI observations with those from ground-based ZSL-DOAS measurements from the polar vortex edge region (Chinese Great Wall station; $62.22^{\circ} \mathrm{S}, 58.96^{\circ} \mathrm{W}$ ) of Antarctica, where rapid changes and large fluctuations in TOC have been detected [36]. Daily average EMI TOCs and ZSL-DOAS TOCs from November 2018 to November 2019 are shown in Figure 9a. The blue line located at 220 DU $\left(1 \mathrm{DU}=2.69 \times 10^{16}\right.$ molecule $\left./ \mathrm{cm}^{2}\right)$ denotes the threshold for the ozone hole [37]. The average absolute difference (at a $95 \%$ confidence interval) was $5.33 \%$. The ozone hole above the Great Wall Station was monitored simultaneously using both EMI and ZSL-DOAS measurements during the observation period. The daily averaged TOC from EMI is consistent with ZSL-DOAS, with an R of 0.90 . 

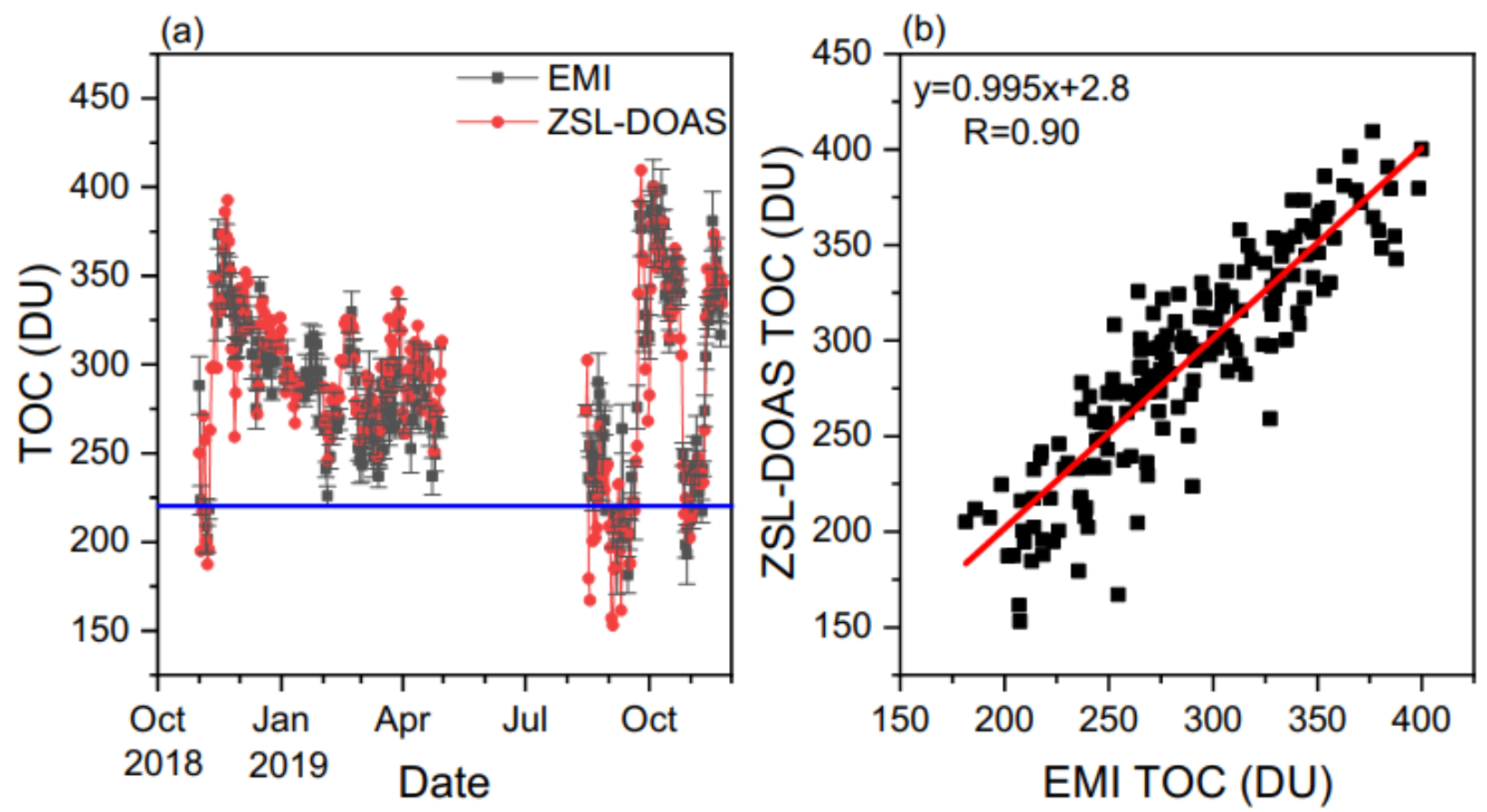

Figure 9. (a) Daily average TOCs from EMI and ZSL-DOAS measurements and (b) linear fitting between EMI and ZSL-DOAS measurements.

In 2019, a sudden stratospheric warming (SSW) event in the Southern Hemisphere increased the average October TOC by $28 \%$ compared to the October average over the previous 11 years [38]. Monthly averaged Antarctic TOCs from EMI in October 2018 and 2019 are shown in Figure 10. The ozone hole is smaller in 2019 compared to 2018, and the monthly average October 2019 TOC is $45 \%$ higher compared to October 2018 in the inland area $\left(60-90^{\circ} \mathrm{S}\right)$, corresponding with the 2019 SSW event. These two examples show that EMI has the capacity to monitor long-term trends in regional TOC and the Antarctic ozone hole.

(a) EMI (October,2018)

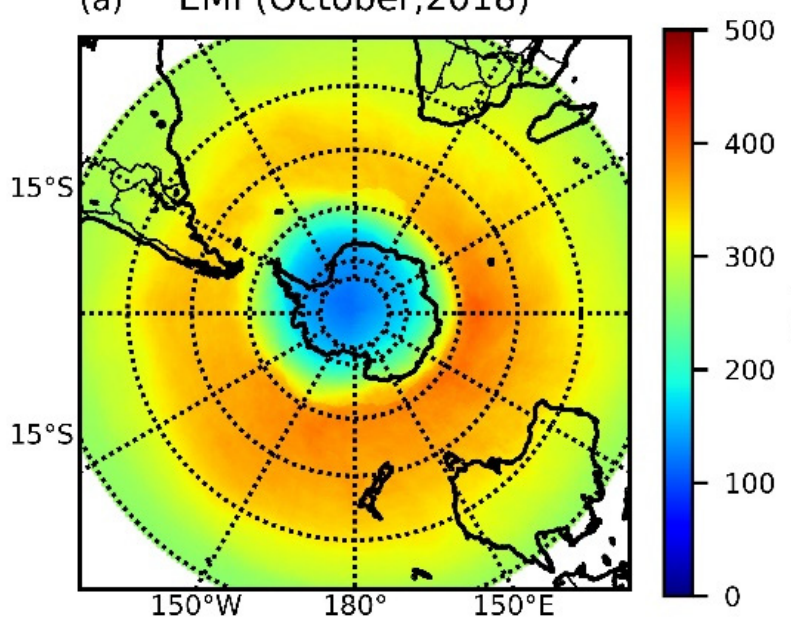

(b) EMI (October,2019)

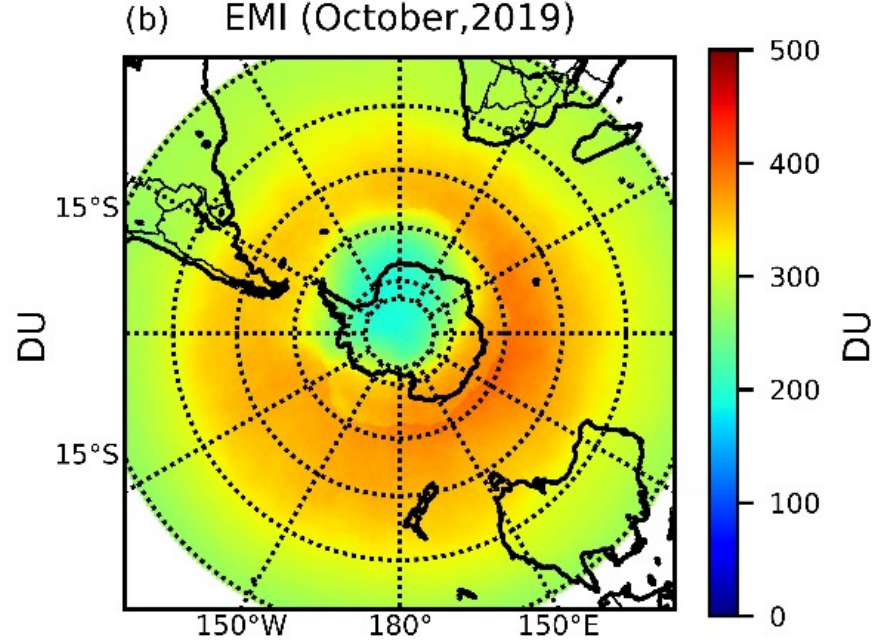

Figure 10. Monthly averaged TOCs for Antarctica in October (a) 2018 and (b) 2019.

\section{Conclusions and Discussions}

In this study, we presented some of the first EMI TOC results using the DOAS method and compared them with TOCs derived from OMI and TROPOMI at a resampled spatial resolution of $0.25^{\circ} \times 0.5^{\circ}$ (lat $\times$ lon). The EMI TOC showed a similar spatial distribution to 
both OMI and TROPOMI, with an R of 0.99 for both. Daily GB measurements of TOC from seven monitoring stations were also used to validate the EMI TOC and stations located in Germany, France, USA, Australia (Brisbane and Melbourne), Argentina, and Antarctica, and had $\mathrm{R}$ of $0.92,0.93,0.95,0.94,0.95,0.95$, and 0.97 , respectively. The average absolute difference between GB measurements and EMI observations was less than 5.5\%, indicating that TOC retrieved from EMI irradiance using the DOAS method is reliable.

Evaluation of the Antarctic ozone hole and ozone depletion, as one of the most important missions of the EMI, will be conducted in future work. Here, we mainly focus on the accuracy of the EMI TOC retrieval. Daily average TOC from EMI observations on the polar vortex edge region (Chinese Great Wall Station) of Antarctica, where rapid changes and large fluctuations in TOC can be detected, were compared with ground-based ZSL-DOAS measurements. The EMI TOC showed similar fluctuations compared with ZSLDOAS measurements during the observation period, with an average absolute difference of $5.33 \%$ and an R of 0.90 . The ozone hole above the Great Wall Station was simultaneously monitored using EMI and ZSL-DOAS measurements during the observation period, and the impact of an SSW event in October 2019 on the ozone hole was analyzed. These results highlight the potential for EMI observations to be used to monitor the ozone hole.

It should be noted that the EMI TOC results of this study are preliminary. More validations with global GB measurements should be conducted in future, and the EMI TOC retrieval algorithm needs further improvement. For example, the EMI cloud product should be updated in the future. The cloud information used in this study was obtained from TROPOMI cloud products, which limits the accuracy of the EMI TOC retrieval algorithm due to the different overpass times of EMI and TROPOMI. Furthermore, the surface albedo algorithm (especially in high-latitude areas) should be improved in the future, and the distribution of ice or snow should be considered when calculating the AMF in future work. Finally, only a single solar irradiance measured on 12 June 2018 in this mission was used as the reference spectrum, and more solar irradiance measurements should be conducted in future missions. The retrieval algorithm of EMI TOC evaluated in this study is valuable for the future development of EMI TOC products.

Author Contributions: Conceptualization, Y.Q., F.S., and Y.L.; methodology, Y.Q.; software, Y.Q., H.Z., D.Y., T.Y., and L.X.; validation, Y.Q. and F.S.; formal analysis, Y.Q. and D.Y.; investigation, Y.Q.; resources, Y.Q., F.S., and Y.L.; writing-original draft preparation, Y.Q.; writing-review and editing, Y.L. and F.S.; visualization, Y.Q.; supervision, Y.L. and F.S.; project administration, F.S.; funding acquisition, F.S. All authors have read and agreed to the published version of the manuscript.

Funding: This research was funded by the National Natural Science Foundation of China (Grant Nos. 41941011 and 41676184) and the Youth Innovation Promotion Association of CAS (Grant No.2020439).

Institutional Review Board Statement: Not applicable.

Informed Consent Statement: Not applicable.

Data Availability Statement: The data presented in this study are available on request from the corresponding author.

Acknowledgments: The authors would like to thank the Ministry of Ecology and Environment Satellite Application Center for Ecology and Environment (SACEE) for providing the EMI level 1 data. The authors thank the Royal Belgian Institute for Space Aeronomy for providing the QDOAS software. We are thankful to NASA for the provisions of OMI and TROPOMI TOC products. The authors also thank the WOUDC database for providing the reliable ground-based TOC data.

Conflicts of Interest: The authors declare no conflict of interest. 


\section{Appendix A}
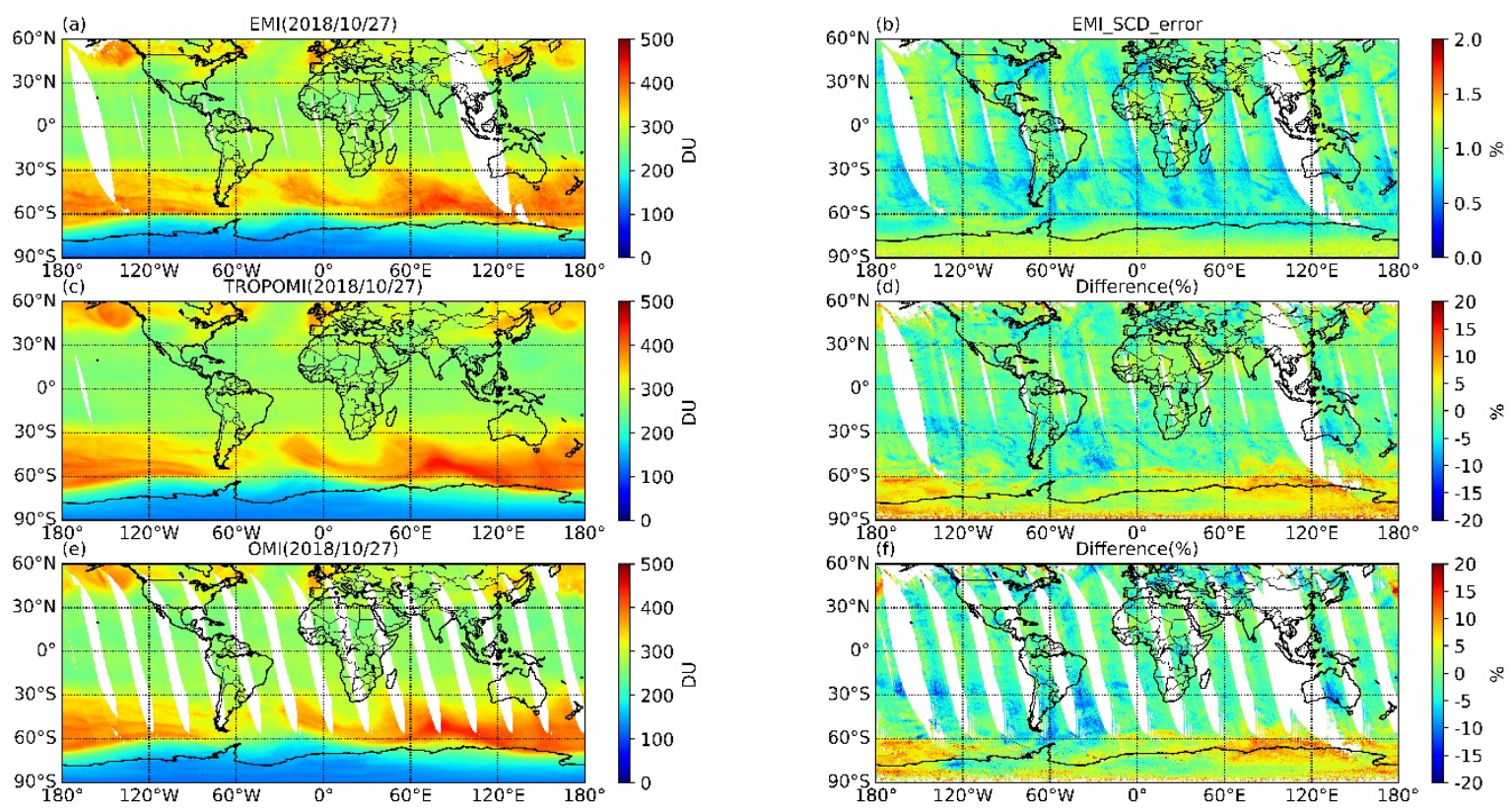

Figure A1. Spatial distribution of (a) daily average EMI TOC, (b) EMI relative daily average SCD error, (c) daily average TROPOMI TOC, (d) average relative difference between EMI and TROPOMI, (e) daily average OMI TOC, and (f) average relative difference between EMI and OMI on 27 October 2018.
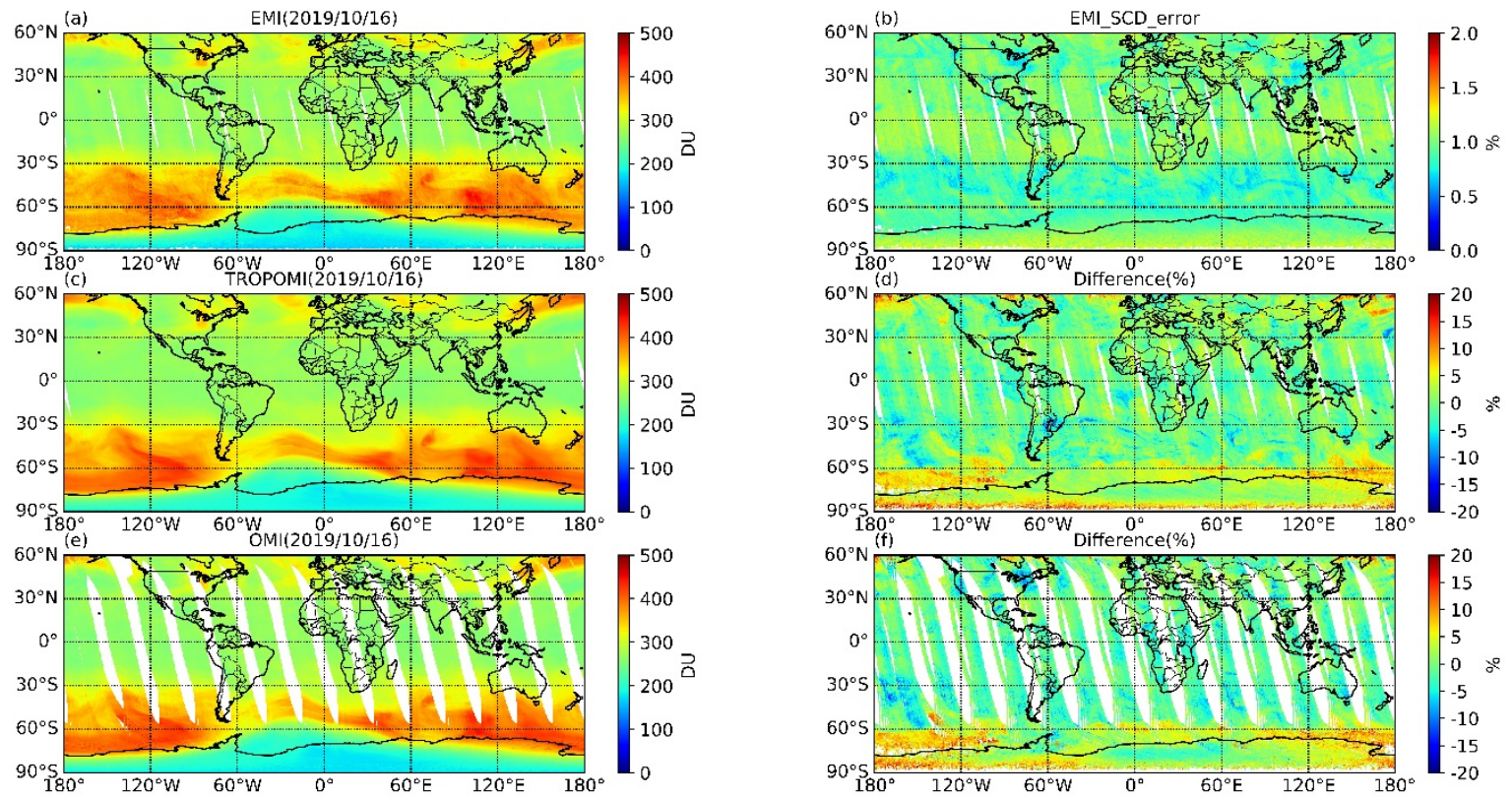

Figure A2. Spatial distribution of (a) daily average EMI TOC, (b) EMI relative daily average SCD error, (c) daily average TROPOMI TOC, (d) average relative difference between EMI and TROPOMI, (e) daily average OMI TOC, and (f) average relative difference between EMI and OMI on 16 October 2019.

\section{References}

1. Li, G.; Tan, Y.K.; Li, C.Y.; Chen, S.C.; Bai, T.; Yang, D.Y.; Zhang, Y. Characteristics of boreal winter total ozone distribution in the northern hemisphere and their relationship with stratospheric temperature during recent 30 years. Chin. J. Geophys. 2015, 58, 213-228. [CrossRef]

2. Bazhenov, O. Increased humidity in the stratosphere as a possible factor of ozone destruction in the Arctic during the spring 2011 using Aura MLS observations. Int. J. Remote Sens. 2019, 40, 3448-3460. [CrossRef] 
3. Paschou, P.; Koukouli, M.E.; Balis, D.; Lerot, C.; Roozendael, M.V. The effect of considering polar vortex dynamics in the validation of satellite total ozone observations. Atmos. Res. 2020, 238, 104870. [CrossRef]

4. Frie $\beta$, U.; Kreher, K.; Johnston, P.V.; Platt, U. Ground-based DOAS measurements of stratospheric trace gases at two Antarctic stations during the 2002 ozone hole period. J. Atmos. Sci. 2005, 62, 765-777. [CrossRef]

5. Nakajima, H.; Murata, I.; Nagahama, Y.; Akiyoshi, H.; Saeki, K.; Kinase, T.; Takeda, M.; Tomikawa, Y.; Jones, N.B. Chlorine partitioning near the polar vortex edge observed with ground-based FTIR and satellites at Syowa station, Antarctica, in 2007 and 2011. Atmos. Chem. Phys. 2020, 20, 1043-1074. [CrossRef]

6. Farman, J.C.; Gardiner, B.G.; Shanklin, J.D. Large losses of total ozone in Antarctica reveal seasonal $\mathrm{CIO}_{x} / \mathrm{NO}_{x}$ interaction. Nature 1985, 315, 207-210. [CrossRef]

7. Solomon, S.; Lvy, D.J.; Kinnison, D.; Mills, M.J.; Neel, R.R.; Schmidt, A. Emergence of healing in the Antarctic ozone layer. Science 2016, 353, 269-274. [CrossRef]

8. Bodeker, G.E.; Shiona, H.; Eskes, H. Indicators of Antarctic ozone depletion. Atmos. Chem. Phys. 2005, 5, 2603-2615. [CrossRef]

9. Kerr, R.A. First detection of ozone hole recovery claimed. Science 2011, 332, 160. [CrossRef]

10. Luo, Y.H.; Si, F.Q.; Liu, W.Q.; Sun, L.G.; Liu, Y. Observations of stratospheric ozone above Ny-Ålesund in the Arctic, $2010-2011$. Adv. Polar Sci. 2015, 26, 256-263. [CrossRef]

11. Veefkind, J.P.; de Han, J.F.; Brinksma, E.J.; Kroon, M.; Levelt, P.F. Total ozone from the ozone monitoring instrument (OMI) using the DOAS technique. IEEE Trans. Geosci. Remote Sens. 2006, 44, 1239-1244. [CrossRef]

12. Loyola, D.G.; Koukouli, M.E.; Valks, P.; Bails, D.S.; Hao, N.; Van Roozendael, M.; Spurr, R.J.D.; Zimmer, W.; Kiemle, S.; Lerot, C.; et al. The GOME-2 total column ozone product: Retrieval algorithm and ground-based validation. J. Geophys. Res. 2011, 116, D07302. [CrossRef]

13. Garane, K.; Koukouli, M.E.; Verhoelst, T.; Lerot, C.; Heue, K.P.; Fioletov, V.; Balis, D.; Bais, A.; Bazureau, A.; Dehn, A.; et al. TROPOMI/S5P total ozone column data: Global ground-based validation and consistency with other satellite missions. Atmos. Meas. Tech. 2019, 12, 5263-5287. [CrossRef]

14. Burrows, J.P.; Weber, M.; Buchwitz, M.; Rozanov, V.; Ladstätter-Weißenmayer, A.; Richter, A.; Debeek, R.; Hoogen, R.; Bramstedt, K.; Eichmann, K.U.; et al. The global ozone monitoring experiment (GOME): Mission concept and first scientific results. J. Atmos. Sci. 1999, 56, 151-175. [CrossRef]

15. Callies, J.; Corpaccioli, E.; Eisinger, M.; Hahne, A.; Lefebvre, A. Gome-2-Metop's second-generation sensor for operational ozone monitoring. ESA Bull. Eur. Space 2000, 102, 28-36.

16. Bovensmann, H.; Burrows, J.P.; Buchwitz, M.; Frerick, J.; Noel, S.; Rozanov, V.V.; Chance, K.V.; Goede, A.P.H. SCIAMACHY: Mission objectives and measurement modes. J. Atmos. Sci. 1999, 56, 127-150. [CrossRef]

17. Wang, Y.M.; Wang, Y.J.; Wang, W.H.; Zhang, Z.M.; Lü, J.G.; Fu, L.P.; Jiang, F.; Chen, J.; Wang, J.H.; Guan, F.J.; et al. FY-3 satellite ultraviolet total ozone unit. Chin. Sci. Bull. 2009, 55, 84-89. [CrossRef]

18. Levelt, P.F.; Joiner, J.; Tamminen, J.; Veefkind, J.P.; Bhartia, P.K.; Stein Zweers, D.C.; Duncan, B.N.; Streets, D.G.; Eskes, H.; van der A, R.; et al. The ozone monitoring instrument: Overview of 14 years in space. Atmos. Chem. Phys. 2018, 18, 5699-5745. [CrossRef]

19. Veefkind, J.P.; Aben, I.; McMullan, K.; Förster, H.; de Vries, J.; Otter, G.; Claas, J.; Eskes, H.J.; de Haan, J.F.; Kleipool, Q.; et al. TROPOMI on the ESA sentinel-5 precursor: A GMES mission for global observations of the atmospheric composition for climate, air quality and ozone layer applications. Remote Sens. Environ. 2012, 120, 70-83. [CrossRef]

20. Platt, U.; Stutz, J. Differential Optical Absorption Spectroscopy: Principles and Applications; Springer: Berlin/Heidelberg, Germany, 2008.

21. Buchard, V.; Brogniez, C.; Auriol, F.; Bonnel, B.; Lenoble, J.; Tanskanen, A.; Bojkov, B.; Veefkind, P. Comparison of OMI ozone and UV irradiance data with ground-based measurements at two French sites. Atmos. Chem. Phys. 2008, 8, 4517-4528. [CrossRef]

22. Cheng, L.X.; Tao, J.H.; Valks, P.; Yu, C.; Liu, S.; Wang, Y.P.; Xiong, X.Z.; Wang, Z.F.; Chen, L.F. $\mathrm{NO}_{2}$ retrieval from the environmental trace gases monitoring instrument (EMI): Preliminary results and intercomparison with OMI and TROPOMI. Remote Sens. 2019, 11, 3017. [CrossRef]

23. Zhang, C.X.; Liu, C.; Chan, K.L.; Hu, Q.H.; Liu, H.R.; Li, B.; Xing, C.Z.; Tan, W.; Zhou, H.J.; Si, F.Q.; et al. First observation of tropospheric nitrogen dioxide from the environmental trace gases monitoring instrument onboard the Gaofen-5 satellite. Light Sci. Appl. 2020, 9, 66. [CrossRef] [PubMed]

24. Zhao, M.J.; Si, F.Q.; Zhou, H.J.; Wang, S.M.; Jiang, Y.; Liu, W.Q. Preflight calibration of the Chinese environmental trace gases monitoring instrument (EMI). Atmos. Meas. Tech. 2018, 11, 5403-5419. [CrossRef]

25. Thomas, H.E.; Watson, I.M.; Simon, A.C.; Prata, A.J.; Realmuto, V.J. A comparison of AIRS, MODIS and OMI sulphur dioxide retrievals in volcanic clouds. Geomat. Nat. Haz. Risk. 2011, 2, 217-232. [CrossRef]

26. Inness, A.; Flemming, J.; Heue, K.P.; Lerot, C.; Loyola, D.; Ribas, R.; Valks, P.; van Roozendael, M.; Xu, J.; Zimmer, W. Monitoring and assimilation tests with TROPOMI data in the CAMS system: Near-real-time total column ozone. Atmos. Chem. Phys. 2019, 19, 3939-3962. [CrossRef]

27. Smedley, A.R.D.; Rimmer, J.S.; Webb, A.R. A more representative "best representative value" for daily total column ozone reporting. Atmos. Meas. Tech. 2017, 10, 4697-4704. [CrossRef] 
28. Bogumil, K.; Orphal, J.; Homann, T.; Voigt, S.; Spietz, P.; Fleischmann, O.C.; Vogel, A.; Hartmann, M.; Kromming, H.; Bovensman, H.; et al. Measurements of molecular absorption spectra with the SCIAMACHY preflight model: Instrument characterization and reference data for atmospheric remote-sensing in the $230-2380 \mathrm{~nm}$ region. J. Photochem. Photobiol. A Chem. 2003, 157, 167-184. [CrossRef]

29. Vandaele, A.C.; Hermans, C.; Simon, P.C.; Roozendael, M.V.; Guilmot, J.M.; Carleer, M.; Colin, R. Fourier transform measurement of $\mathrm{NO}_{2}$ absorption cross-section in the visible range at room temperature. J. Atmos. Chem. 1996, 25, 289-305. [CrossRef]

30. Vandaele, A.C.; Hermans, C.; Fally, S. Fourier transform measurements of $\mathrm{SO}_{2}$ absorption cross sections: II.: Temperature dependence in the 29000-44000 $\mathrm{cm}^{-1}$ (227-345 nm) region. J. Quant. Spectrosc. Ra. 2009, 110, 2115-2126. [CrossRef]

31. Fleischmann, O.C.; Hartmann, M. New ultraviolet absorption cross-sections of $\mathrm{BrO}$ at atmospheric temperatures measured by time-windowing Fourier transform spectroscopy. J. Photochem. Photobiol. 2004, 168, 117-132. [CrossRef]

32. Meller, R.; Moortgat, G.K. Temperature dependence of the absorption cross sections of formaldehyde between 223 and $323 \mathrm{~K}$ in the wavelength range 225-375 nm. J. Geophys. Res. 2000, 105, 7089-7101. [CrossRef]

33. Wellemeyer, C.G.; Bhartia, P.K.; Taylor, S.L.; Qin, W.; Ahn, C. Version 8 total ozone mapping spectrometer (TOMS) algorithm. Quadrenn. Ozone Symp. 2004, I, 635-636.

34. Kleipool, Q.L.; Dobber, M.R.; de Haan, J.F.; Levelt, P.E. Earth surface reflectance climatology from 3 years of OMI data. J. Geophys Res. Atmos. 2008, 113. [CrossRef]

35. Boersma, K.F.; Eskes, H.J.; Veefkind, J.P.; Brinksma, E.J.; Sneep, M.V.; Van den Oord, G.H.; Levelt, P.F.; Stammes, P.; Gleason, J.F.; Bucsela, E.J. Near-real time retrieval of tropospheric $\mathrm{NO}_{2}$ from OMI. Atmos. Chem. Phys. 2007, 7, 2103-2118. [CrossRef]

36. Qian, Y.Y.; Luo, Y.H.; Si, F.Q.; Yang, T.P.; Yang, D.S. Three-year observations of ozone columns over polar vortex edge area above West Antarctica. Adv. Atmos. Sci. 2021. [CrossRef]

37. Bodeker, G.E.; Struthers, H.; Connor, B.J. Dynamical containment of Antarctic ozone depletion. Geophys. Res. Lett. 2002, $29,2-1-2-4$. [CrossRef]

38. Safieddine, S.; Bouillon, M.; Paracho, A.C.; Jumelet, J.; Tence, F.; Pazmino, A.; Goutail, F.; Wespes, C.; Bekki, S.; Boynard, A.; et al. Antarctic ozone enhancement during the 2019 sudden stratospheric warming event. Geophys. Res. Lett. 2020, 47, e2020GL087810. [CrossRef] 